\title{
THE DESIGN OF A TESTING DEVICE FOR PASSIVE INFRARED MOTION DETECTORS
}

\author{
MILAN KUTAJ, L'UBOŠ JASENČÁK, ANDREJ VELAS \& MARTIN BOROŠ \\ Department of Security management, Faculty of Security engineering, University of Zilina, Slovakia
}

\begin{abstract}
As part of research and development work at the Department of Security management of the University of Zilina, we concerned ourselves with testing various types of motion detectors. Testing of detectors in general serves to acquire a basis of data for software developed at the Faculty, which serve to measure and evaluate the levels of physical security of an object. Detectors are tested at the faculty in terms of reliability and breach resilience. We are mostly interested in the time it takes to detect an intruder. Until now, we have not tested several detectors at once. Testing of a larger pool of detectors at the same time is useful when comparing their detection capabilities and when testing the ability of the alarm system control unit and its load capacity. The article contains a concept, design, blueprint and principle of operation of a testing device, designed to test a greater number of passive infrared motion detectors at one, works. The designed testing device allows for testing the detection ability of several motion detectors at once, compare the time it takes them to disconnect their NC contacts and also compare the reaction times of individual motion detectors. The article also contains a description of the device's structure and recording of the acquired results which is based on a free Arduino platform and their usability in practice. The proposed device will be further improved as part of our R\&D activities.
\end{abstract}

Keywords: test equipment, motion detector, infrared.

\section{INTRODUCTION}

A Passive Infrared Detector is a detector of a wide spectrum infrared radiation emitted by a human [1]. Passive infrared motion detectors are among the most used components of electronic security systems. They have other applications (home automation, car security, etc) to detect motion of persons. They basically are very simple, not overly complex devices with their production costs starting at just a few Euro, but can climb up to several hundred Euros based on the added circuits. The main requirements on electronic security systems, components of which are motion detectors, and thus also passive infrared detectors (PIR), are stated by norm STN EN 50131 Alarm systems - Electronic security and distress alarm systems. Part of the norm known as 2-2: Intrusion detectors - Passive infrared detectors determines the conditions for testing PIRs [1]. According to research already realized, passive infrared detectors do not have a success rate of 1 , therefore they have some shortcomings. These can only be evaluated and measured by a qualified person and the measurements can be performed in an environment where the systems are going to be installed and used (however, such testing does not provide conclusions for all components of the system), or in laboratory conditions. Before being introduced on the market, the PIR detectors must be tested by their manufacturers in accredited laboratories (proving grounds) such as at VdS in German, IMQ in Italy, TESTALARM in Prague, Czech Republic, Telefication in The Netherlands, etc. After fulfilling all the norm-prescribed conditions (EN, TUV, GOST-R, INCERT and others), the manufacturer is issued a certificate (or provides a declaration of conformity with each the product). The certification itself concerns not only detection capabilities, but also electromagnetic compatibility, safety from injury caused by the product, protection from the effects of the environment, radiation, and other parameters [1]-[3]. For the needs of protecting secret information within The Slovak Republic, PIR detectors are tested once more on testing laboratories accredited by the National Security Authority. For 
the needs of using PIR detectors in explosive environments, there are separate certification processes (in accordance with the EN 60079 norms) [4].

We tested the submitted series of detectors. In case of a manufacturing error, long-term usage or a change in technological processes during manufacturing, it is possible the properties of the PIR detector will change, which the certification has no effect on. Since there are small series of products submitted for testing, it could be interesting to compare the detection capabilities of the detectors when choosing random detectors of the same type or the same production series, installed in the same environment and keeping to the same installation parameters. Whole measurement process and research methodology are shown on Fig. 1.

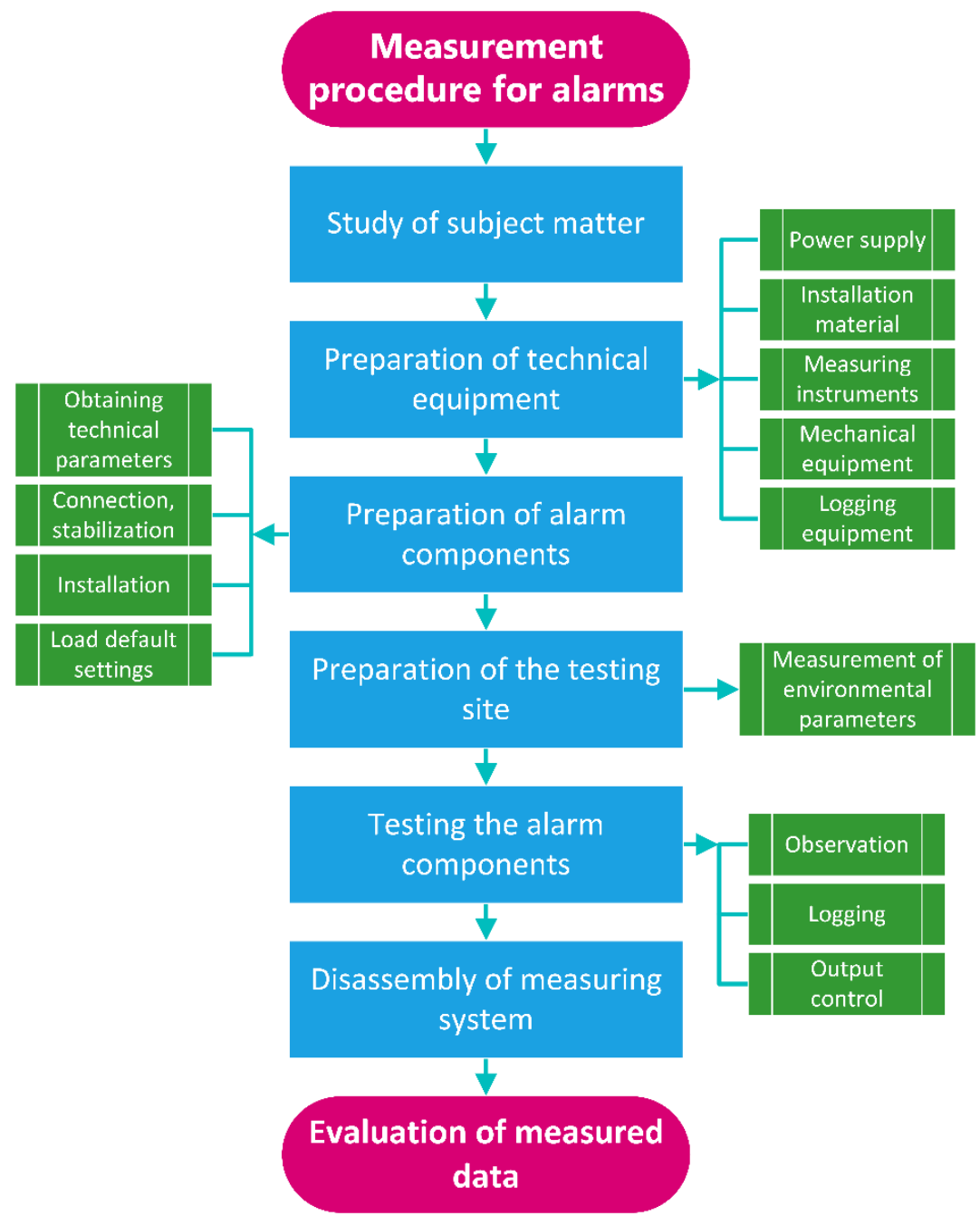

Figure 1: Diagram of research approach to measurement process. 


\section{DESIGN OF THE TESTING DEVICE}

Due to the aforementioned aspects and unique nature of the tests of individual detectors, we considered designing a device for bulk testing of motion detectors. In principle, it would be a simple sheet with several motion detectors of the same type from the same manufacturer or multi-item series of several detectors, which would allow for their comparison. The structure of the sheet would consist of hollow polycarbonate or KömaTex (PVC sheet). To attach the detectors, a modular system was considered due to different sizes of the individual PIR detectors. This could mean clamps $\left(360^{\circ}\right.$ degree rotating holster) similar to those used to attach mobile phone or GPS devices in vehicles [5].

The detector must be attached to the sheet in a way that allows for its quick replacement, should the circumstances require it. We considered RJ45 connectors as well as RJ11s however, these require the use of crimping pliers. For this reason, ultimately, the most convenient connector is one that snaps into place and does not require the use of a screwdriver or pliers.

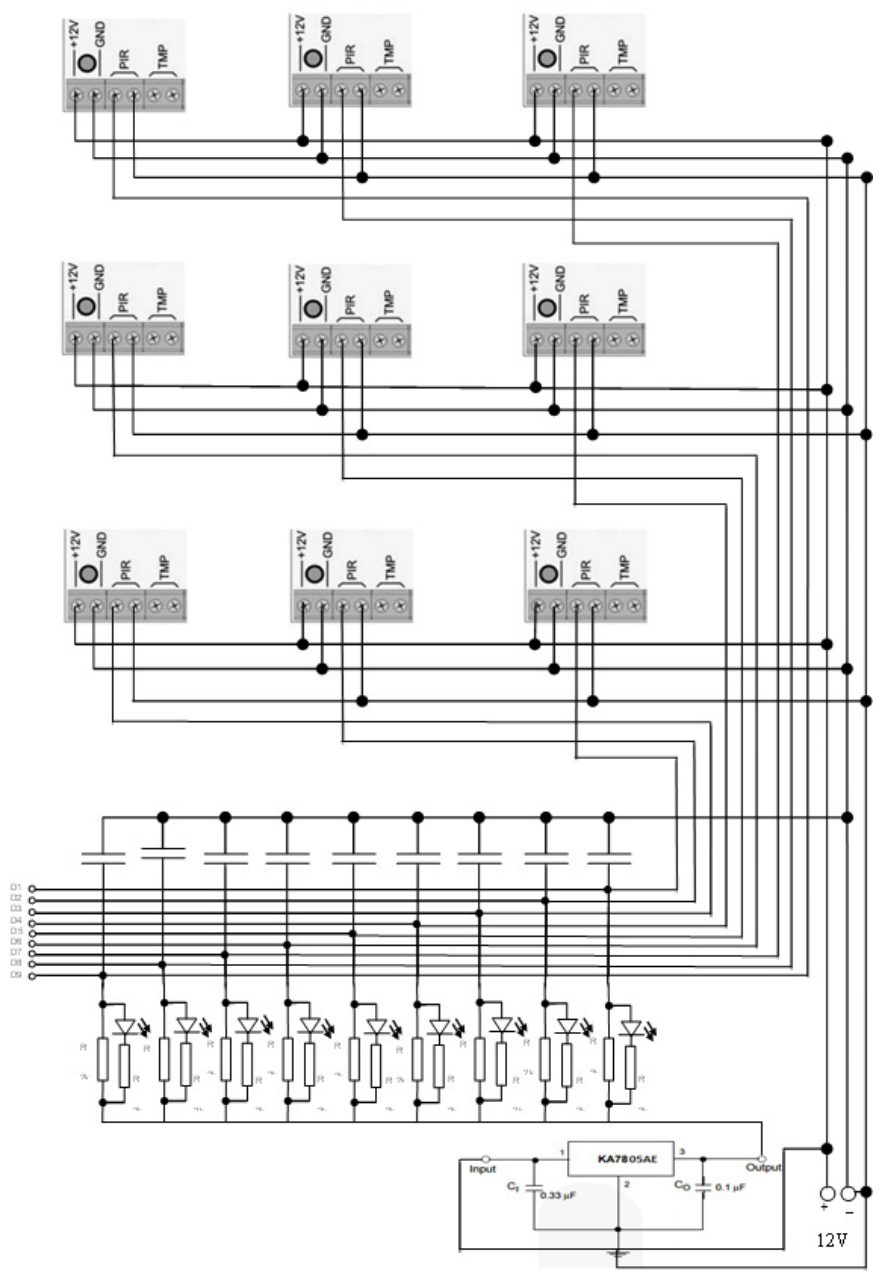

Figure 2: Diagram of tamper-free connection of the detectors. 


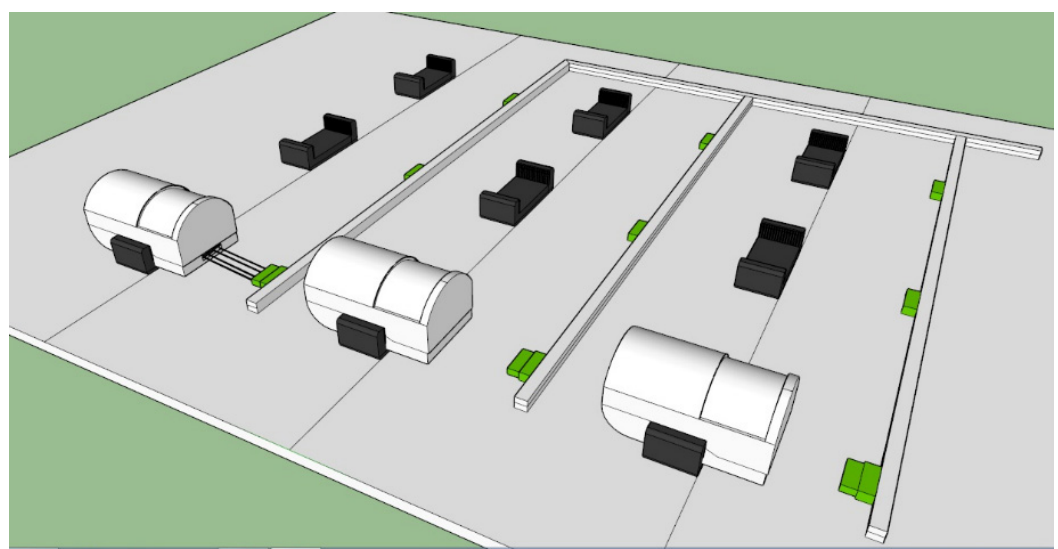

Figure 3: Preliminary design of the testing device - tableau.

The overall construction of the testing device must allow for a quick PIR detector installation, simple connectivity, recording and reliable evaluation of results. The next figure showcases the visualization of the testing device in form of a tableau.

It is clear from the diagram that the detection characteristics of the installed motion detectors will be moved by the distance between these installed detectors.

\section{THE PROCESS OF RECORDING RESULTS AND RESEARCH QUESTIONS}

The testing device is affixed to a wall and a person passing by in front of the device (which is considered a standard detection target as defined by the STN EN 50131 norm) simulates motion. The movement of the person should be detected by the detectors. We will evaluate whether all detectors in a line manage to detect the motion. This is why individual detector types are connected in a line. If some of them do not detect the motion, we will investigate the reason for this phenomenon.

The way of recording results should be simple and exact. We considered using optical signalization by connecting a resistor and an LED to each of the detectors, which would light up upon detecting motion. The testing process would then be recorded by a camera system. Evaluating the camera footage would be somewhat complicated, however. One of the options is connecting each detector into an individual ESS control unit loop. This way, we would be limited by the number of wired inputs of the control unit and its software capabilities. This is why we opted for creating an evaluation device from the Arduino construction set modules. It is an open-source, relatively simply programmable platform. The module allows for recording 12 states onto an SD card, which is sufficient, since we chose a tableau with 9 detectors. In case of PIR detectors, the output of one detector is disconnecting its NC contacts, therefore it is a potential-free output. By moving the detection target in front of the testing device - tableau, all detectors in one line should become disconnected.

The material list for the device is as follows:

- $\quad$ sheet made of hollow polycarbonate, $6 \mathrm{~mm}$ thick, or the alternative KömaTex sheet $3050 \times 1220 \mathrm{~mm}$,

- 9 universal holders,

- 9 connectors, 
- $\quad$ attaching the holders and connectors using screws or an adhesive,

- evaluation device Arduino ATmega32u4 (12 inputs) + SD card Data Logger,

- cables [5].

According to analysis of possibilities of mentioned above testing device we can formulate research questions:

1. Is there any limitation for number of tested PIR detectors?

2. Is it possible to test bus-based PIR detectors?

Based on the pilot testing performed and values acquired from the recording of the states of the tested PIR detectors throughout a time period, we can further work with this data and formulate conclusions through comparison. In the testing phase, we chose 50 walk-by perpendicular to the axis of the detectors, 2 meters away from the testing device.

Based on the pilot tests results (Table 1), it is clear that the tableau is functional and usable for testing passive infrared motion detectors. Detections can be recorded in terms of the detection time. As an example, we have selected an image of detections over time in the interval between 9:44:04 and 9:44:48. Our first comparison, shown on the following figure, is between detectors at positions 1,4 and 7 .

The chart (Fig. 4) allows for evaluation and comparing the time necessary for the NC contacts disconnection. This represents a time interval between opening the NC contact and its closing, i.e. the return into a normal state when the detector is ready to again detect the target within its detection characteristics.

Table 1: Results of pilot tests.

\begin{tabular}{|c|c|c|c|c|c|c|}
\hline \multicolumn{2}{|c|}{ Detector position } & $\begin{array}{c}\text { Number } \\
\text { of } \\
\text { detections }\end{array}$ & $\begin{array}{c}\text { Number } \\
\text { of missed } \\
\text { detections }\end{array}$ & $\begin{array}{c}\text { Detection } \\
\text { ratio }\end{array}$ & Miss ratio & Overall \\
\hline $\begin{array}{c}\text { Line of } \\
\text { Tested PIR } \\
\text { detectors } \\
\text { no.1 }\end{array}$ & D1 & 50 & 0 & $100 \%$ & $0 \%$ & $100 \%$ \\
\cline { 2 - 7 } & D2 & 50 & 0 & $100 \%$ & $0 \%$ & $100 \%$ \\
\hline $\begin{array}{c}\text { Line of } \\
\text { Tested PIR } \\
\text { detectors } \\
\text { no.2 }\end{array}$ & D4 & 50 & 0 & $100 \%$ & $0 \%$ & $100 \%$ \\
\cline { 2 - 7 } & D6 & 50 & 0 & $100 \%$ & $0 \%$ & $100 \%$ \\
\hline $\begin{array}{c}\text { Line of } \\
\text { Tested PIR } \\
\text { detectors } \\
\text { no.3 }\end{array}$ & D7 & 50 & 0 & $100 \%$ & $0 \%$ & $100 \%$ \\
\cline { 2 - 7 } & D9 & 50 & 0 & $100 \%$ & $0 \%$ & $100 \%$ \\
\hline
\end{tabular}




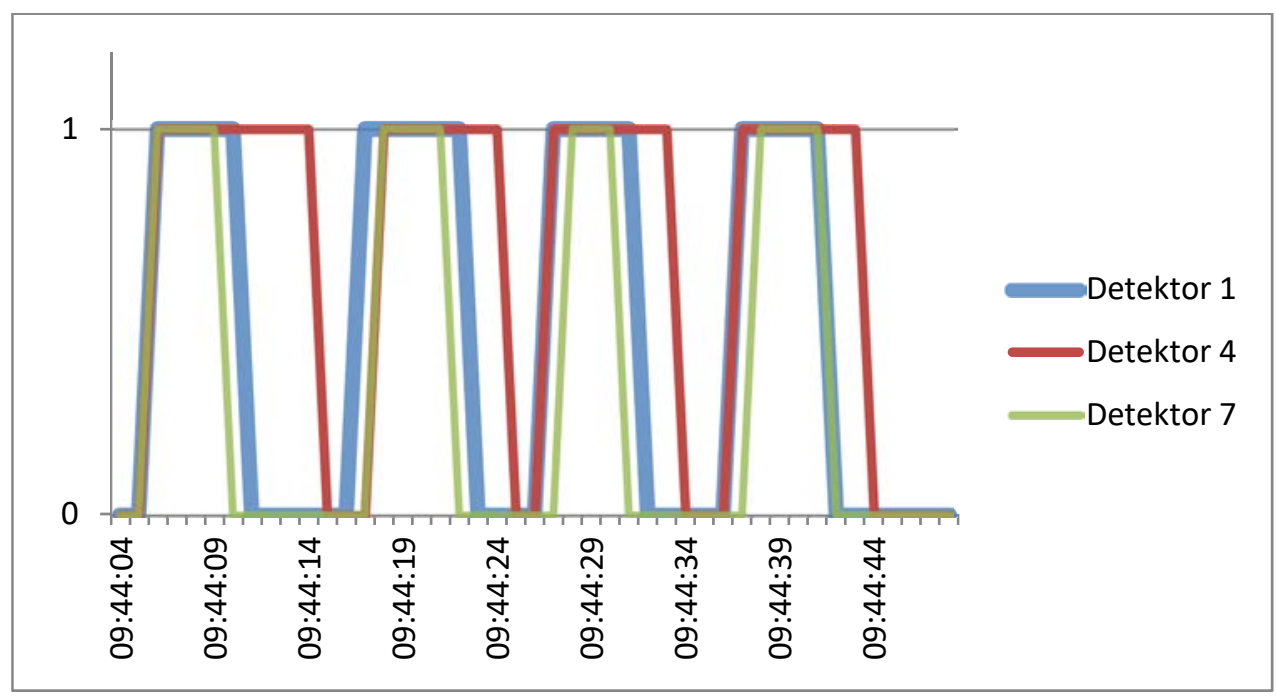

Figure 4: Comparison of testing proceedings between detectors at positions 1, 4 and 7.

The charts also show and allow for comparison of the reaction speeds of individual detectors placed over each other or to read it out of the graph and compare detectors in each line.

\section{CONCLUSION}

This article has presented a concept, design, blueprint and principle of operation for a testing device aimed at testing 9 detectors at a time. Answer to the first question is that the end number of detectors is not technologically limited; it is possible to use larger tableaus and more modules of the Arduino construction set and connect them accordingly. In practice, the designed testing device is useful for testing a large number of detectors of a single type from the same manufacturer or several detectors in individual lines of detection $(3 \times 3$ types of detectors). Unfortunately, answer to the second question is no positive. There is no possible way to test bus-based detectors using the tableau because communication protocols are encrypted and they cannot work without ESS control panel. The testing device allows us to verify, in practice, the reliability of motion detection using passive infrared detectors, compare their detection times and the length of time required to disconnect their NC contacts. The device can also serve to find out the influence of height at which the detectors are installed on the detection capability.

\section{ACKNOWLEDGEMENT}

This article was published with the support of the VEGA Project no. 1/0455/16 titled Analysis of options for increasing the safety of citizens and their property in municipalities through prevention.

\section{REFERENCES}

[1] STN P CLC/TS 50131-2-2 Poplachové systémy. Elektrické zabezpečovacie systémy. Čast' 2-2: Detektory narušenia. Pasívne infračervené detektory. 
[2] STN EN 50131-1 Poplachové systémy. Elektrické zabezpečovacie systémy. Čast' 1: Všeobecné požiadavky.

[3] EN 50130-5 Alarm systems - Part 5: Environmental test methods.

[4] Lovecek, T., Ristvej, J. \& Simak, L., Critical infrastructure protection systems effectiveness evaluation. Journal of Homeland Security and Emergency Management. ISSN 1547-7355, 7(1) p. 34, 2010.

[5] Jasenčák, L., Testovanie spol'ahlivosti a časov spracovania signálov detektorov pohybu. [Diplomová práca]. Žilinská univerzita v Žiline. Fakulta bezpečnostného inžinierstva; Katedra bezpečnostného manažmentu. Žilina FBI ŽU, 2016. 86 s. 